\title{
Risk of Human Immunodeficiency Virus Type 1-Related Neurologic Disease in a Cohort of Intravenous Drug Users
}

Karen Marder, MD, MPH; Xinhua Liu, PhD; Yaakow Stern, PhD; Renée Malouf, MDt; George Dooneief, MD, MPH; Karen Bell, MD; George Todak, CSW; Maryse Joseph, RN; Stephen Sorrell, MDt; Wafaa El Sadr, MD; Janet B. W. Williams, DSW; Anke Ehrhardt, PhD; Zena Stein, MD; Jack Gorman, MD

Baekground: Although the proportion of cases of acquired immunodeficiency syndrome related to intravenous drug use has increased dramatically over the past decade, there has been no longitudinal examination of primary neurologic disease in this group.

Objective: To study the development of neurologic disease in human immunodeficiency virus (HIV)-negative and HIV-positive men and women who were intravenous drug users over a 3.5-year period.

Design: Prospective observational cohort study.

Setting: Subjects were recruited from an infectious disease clinic at a New York City Hospital or from a methadone maintenance program.

Participants: Ninety-nine HIV-negative (62 men and 37 women) and $124 \mathrm{HIV}$-positive (85 men and 39 women) intravenous drug users volunteered.
Main Outcome Measure: The development of clinically significant manifestations in six neurologic domains.

Resulfs: With multivariate adjustment for current and past substance abuse, age, education, and head injury, we examined the odds of developing HIVrelated neurologic disease. Extrapyramidal signs and reduced motor ability became increasingly apparent over time in HIV-infected men as their CD4 cell count declined and as the subjects developed the acquired immunodeficiency syndrome. Fewer neurologic signs were seen in the women.

Conclusions: The impact of HIV infection among intravenous drug users parallels that in homosexual men and is independent of alcohol and other drug use.

(Arch Neurol. 1995;52:1174-1182)
†Deceased.

The affiliations of the authors appear in the "acknowledgment" section on page 1181

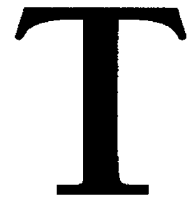

HE PROPORTION of cases of acquired immunodeficiency syndrome (AIDS) related to intravenous drug use has increased dramatically over the past decade and is currently estimated at $34 \% .{ }^{1-3}$ Although a number of studies ${ }^{4-6}$ have addressed the neuropsychologic findings in intravenous drug users (IDUs) who were followed up for 1 year, no longitudinal examination of the neurologic findings in human immunodeficiency virus (HIV)infected IDUs has been reported.

In a cross-sectional analysis, we ${ }^{7}$ have previously found that HIV-positive IDUs had evidence of extrapyramidal signs (EPS) and that the neurologic findings were more severe in those with AIDS-related complex (ARC) than in those with few or no systemic signs of illness. In this study, we performed detailed prospective neurologic examinations biannually to address the following questions: (1) Are there spe- cific neurologic signs attributable to HIV infection independent of the effects of substance abuse, age, education, and history of head injury with loss of consciousness? (2) Are there differences in the neurologic profiles in men and women? (3) What is the relationship between neurologic outcomes and stage of illness and immune status? (4) What is the relationship between neurologic and neuropsychologic outcome measures?

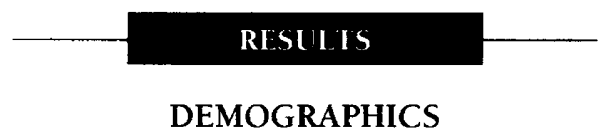

Demographic characteristics of the cohort are presented in Table 2. The CD4

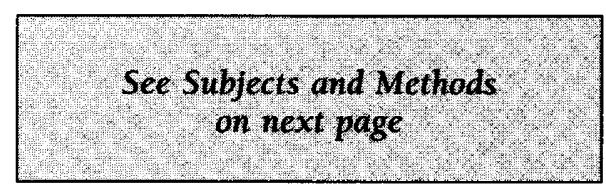




\section{SUBJECTS AND METHODS}

\section{SUBJECTS}

Two hundred twenty-three IDUs (99 HIV-negative and 124 HIV-positive) were recruited in late 1988 through 1989 to participate in a 5-year follow-up study. These included 147 men ( $85 \mathrm{HIV}$-positive and $62 \mathrm{HIV}$-negative) and 76 women (39 HIV-positive and 37 HIV-negative). Subjects were recruited from the Harlem Hospital Infectious Disease Clinic $(n=170)$ and from the St Luke's- Roosevelt Methadone Maintenance Clinic $(n=53)$ (both in New York, NY). Inclusion and exclusion criteria and screening procedures have been described elsewhere. ${ }^{8}$ All subjects were volunteers, and all gave informed consent. All participants had used intravenous drugs at least 10 times since 1982 and met the Diagnostic and Statistical Manual of Mental Disorders, Revised Third Edition ${ }^{9}$ criteria for substance abuse. All subjects who entered the longitudinal phase were examined every 6 months for up to eight visits (a 3.5-year period).

\section{ASSESSMENTS}

At each visit, subjects received a standardized medical examination to stage HIV severity, a neurologic assessment, and a neuropsychologic assessment. Demographic information, substance abuse history, and history of head injury with loss of consciousness were obtained. Laboratory studies at each visit included complete blood cell count and lymphocyte typing. Information on the prevalence of human T-cell lymphotropic virus types I and II was obtained at visit 2 only.

\section{Medical Assessment}

Physicians performed physical examinations targeted at HIVrelated symptoms and signs. During follow-up, subjects were characterized as HIV-negative, HIV-positive but physically asymptomatic, HIV-positive and mildly symptomatic, symptomatic but not meeting the criteria for AIDS (ARC), and with AIDS. Nomenclature and staging reflect the 1986 Centers for Disease Control (Atlanta, Ga) staging system. ${ }^{10,11}$

\section{Neurologic Assessment}

Neurologic examinations were performed by neurologists who were blind to the HIV status of the subjects. To maintain them blind, the neurologic examinations were performed prior to the elicitation of symptoms. A standard neurologic examination was performed. Items from the motor portion of the
Unified Parkinson's Disease Rating Scale ${ }^{12}$ were included to assess extrapyramidal function. Each neurologic sign was coded separately so that individual signs could be examined and factor scores could be created based on individual items. Neurologic symptoms were elicited using the structured interview created by Price et al. ${ }^{13}$ Reliability of the neurologic examination was good to excellent. ${ }^{14}$

The neurologic data were summarized in two ways. First, an overall measure of neurologic disability was determined for each subject, based on the Kurtzke Disability Status Scale for Multiple Sclerosis. ${ }^{15}$ This previously described scale ${ }^{16}$ reflects both the number of areas of neurologic dysfunction (ie, pyramidal tract, cerebellar area, and brain stem) and the severity of impairment. A score of 3 or greater indicates a level of impairment that most neurologists would reliably detect and consider clinically meaningful and would describe someone with moderate neurologic disability who was fully ambulatory.

Neurologic data were also summarized in a factor analysis on selected items of the neurologic examination. ${ }^{7}$ Six factors have proved stable over the eight visits and represent major neurologic domains. Each factor was dichotomized at a level believed to indicate clinical significance, rather than considering the factors as continuous variables. Factors were dichotomized because, for example, it is not clear that the difference between a score of 1 and 2 is the same as between 2 and 3 on the release reflexes factor. It is also easier to interpret the odds of having clinically meaningful signs than to interpret the odds of developing an increase of one point on a specific factor. The six factors and the scores used to dichotomize them into high and low are shown in Table $\mathbf{1}$.

\section{Neuropsychologic Assessment}

The neuropsychologic battery was created to capture a wide range of deficits and has been previously reported. ${ }^{7}$ To reduce the number of test scores, six neuropsychologic factors were constructed, based on those used in the analyses of homosexual men. ${ }^{17}$ These included (1) memory: selective reminding test total score ${ }^{18} ;(2)$ motor speed: grooved pegboard ${ }^{19}$ (time to insert pegs with dominant hand); (3) executive: odd man out total score ${ }^{20}$ and Trail $B^{21}$ time; (4) language: Controlled Oral Word Association Test $(60 \mathrm{sec}$ onds for each of the letters $\mathrm{C}, \mathrm{F}$, and L) and animal naming $^{22}$; (5) attention: digit symbol age-scaled score ${ }^{23}$ and space and letter cancellation time $\mathrm{e}^{24}$, and (6) orientation: orientation score from Mini-Mental State examination. ${ }^{25}$ Summary scores were calculated for each subject by transforming component scores into $z$ scores based on the mean and

Continued on next page cell count was significantly lower $(P<.001)$ and the neurologic disability score was significantly higher $(P<.01)$ in HIV-positive subjects compared with HIV-negative subjects. Men were significantly older $(P<.05)$ but had significantly lower neurologic disability scores $(P<.01)$ than women, indicating that men had less neurologic disease at baseline. Of note, the HIV-negative women had higher mean disability scores at baseline than the HIV-negative men; in fact, their scores were similar to those of the HIVpositive men. Men were significantly more likely to be substance abusers; the frequency of ethanol use for at least 20 years and heroin or cocaine use for at least 15 years was significantly greater for men $(P<.01)$. Reported long-term substance abuse did not differ by HIV status at baseline. Men were also significantly more likely to report head injury with loss of consciousness than were women $(P<.05)$. None of the subjects were positive for human T-cell lymphotropic virus type I. There was no difference in the human T-cell lymphotropic virus type II seroprevalence among HIV-negative and HIV-positive men and women. 
SD of the test scores of all subjects at the baseline visit. The factor scores were the sum of the $z$ scores that were adjusted for direction and for measures within each factor and were analyzed as continuous variables.

\section{EVALUATION OF ALCOHOL AND OTHER DRUG USE}

\section{Substance Abuse History}

All subjects were systematically interviewed at each visit about their alcohol and other drug usage. Use of all forms of heroin, cocaine, benzodiazepines, hallucinogens, and phencyclidine were queried. We created a variable to reflect the length of time subjects used heroin, all forms of cocaine, or alcohol. The number of years of drug use was highly correlated with the age of the subjects, so the usage variable included both age and years of drug use. Years of illicit drug use were dichotomized into long ( $\geq 15$ years) or short ( $<15$ years), and alcohol use was also dichotomized into long ( $\geq 20$ years) or short ( $<20$ years). If either alcohol or other drug use was considered long, the subject was considered to have a long history of substance abuse. No women over age 40 years and no men over age 45 years had a short history of alcohol or other drug use. Therefore, a variable with only three possible categories was created. Women were classified as age 40 years or younger with short substance use, 40 years or younger with long substance use, and over age 40 years with long substance use. Women aged 40 years or younger with short substance abuse were used as the reference group. Men were similarly divided into three age and substance abuse groups, using age 45 years or younger as a cut point. In this way, the proportion of subjects' lives during which they used alcohol or other drugs was captured.

\section{Recent Substance Abuse History}

The frequency of substance abuse in the 6-month interval prior to the assessment was dichotomized into high for weekly or daily use and low for monthly or less frequent use. Data on recent substance abuse were available only for visits 2 through 7 .

\section{STATISTICAL ANALYSIS}

The baseline characteristics of the HIV-positive and HIVnegative subjects were analyzed using a two-way analysis of variance for continuous variables and logistic analyses for binary variables, with HIV status and gender as main effects.

To take into account the multiple visits per subject and the fact that the characteristics of a single individual over time are likely to be correlated, a generalized estimating equations approach ${ }^{26}$ was used. In this analysis, the repeated measures for each subject (up to eight measures per variable) are treated as a cluster. The generalized estimating equation approach takes into account the status or changing value of covariates and outcomes at each visit. It provides estimates of the odds of the occurrence of an outcome dependent on the values of covariates. The outcome variables included the six neurologic domains and a modified Disability Status Scale, as described above. Odds ratios (ORs), rather than relative risks, were calculated because the analysis includes both prevalent cases, ie, those who have reached the outcome at baseline, and incident cases.

Because of the significant differences in baseline age and disability scores between men and women, as well as the different pattern of substance abuse, data for women and men were always analyzed separately.

The first set of analyses included either all women or all men and examined the effect of HIV status on the odds of developing each neurologic outcome, defined as a high factor score. We also examined changes in these odds over subsequent visits.

The second set of analyses, again considering women and men separately, was restricted to the HIV-positive subjects. The outcome variables (six neurologic domains and measure of general neurologic disability) were examined and adjusted for age, education, alcohol or other drug use, and history of head injury. We included immune status (CD4 cell count) and stage of HIV infection as covariates in two separate analyses of the HIV-positive women and men. The CD4 cell count was treated as a categorical variable; subjects were classified as those having CD4 cell counts of $0.2 \times 10^{9} / \mathrm{L}$ or less and those having $0.2 \times 10^{9}$ to $0.5 \times 10^{9} / \mathrm{L}$, with those having a CD4 cell count of $0.5 \times 10^{9} / \mathrm{L}$ or greater as a reference group. This categorization was designed to capture the subjects who would currently meet the 1992 Centers for Disease Control and Prevention criteria for AIDS, ie, those with a CD 4 cell count of $0.2 \times 10^{9} / \mathrm{L}$ or less. Subjects were also classified into those satisfying the criteria for ARC and those with AIDS, while those with mild symptoms or no symptoms were considered the reference group.

In a third set of analyses, restricted to HIV-positive men and women, the relationship between neurologic disability and neuropsychologic impairment was examined by a linear regression model with repeated measures.
The use of zidovudine was not included in any of the models because usage was not widespread and the length of treatment was limited. Information on zidovudine use was available only from visits 2 through 7 . Only one subject reported zidovudine use at visit 2 . By visit 3 , 55 subjects reported having been treated with zidovudine, but only 16 subjects were taking zidovudine at that visit. At visit 4, 35 subjects were taking zidovudine; at visit 5 , eight; at visit 6 , four; and at visit 7 , two subjects were taking zidovudine.

None of the 124 HIV-positive subjects met the 1986 criteria for AIDS at baseline. A similar proportion of men and women had no symptoms $(27.1 \%$ men and $23.1 \%$ women), mild symptoms ( $28.2 \%$ men and $15.4 \%$ women), or met the criteria for ARC (44.7\% men and $61.5 \%$ women). The proportion of men and women with a CD4 cell count of $0.2 \times 10^{9} / \mathrm{L}$ or less was also similar $(25.9 \%$ men and $23.1 \%$ women).

There were 32 deaths ( 22 men and 10 women), and 32 subjects ( 24 men and eight women) were unavailable for follow-up (they did not complete all eight visits, but they did not die) among the HIV-positive subjects. Among HIV-negative subjects, there were four deaths and 35 subjects were unavailable for follow-up (19 men 
and 16 women). One HIV-negative woman seroconverted during follow-up and subsequently died; she was counted among the HIV-positive subjects who died. Two of the HIV-positive subjects died soon after completing their eighth visit and were considered among those who died. Baseline CD4 cell counts in men (mean count $\pm S D$, $[0.23 \pm 0.18] \times 10^{9} / \mathrm{L}$ ) and in women (mean count $\pm S D$, $\left.[0.23 \pm 0.23] \times 10^{9} / \mathrm{L}\right)$ who died differed significantly from those in HIV-negative men (mean count $\pm S D$, [ $1.12 \pm 0.32] \times 10^{\circ} / \mathrm{L}$ ), HIV-negative women (mean count $\pm S D,[1.15 \pm 0.30] \times 10^{9} / \mathrm{L}$ ), and HIV-positive subjects who were unavailable for follow-up but were not known to have died (mean count $\pm S D,[0.49 \pm 0.25]$ $\times 10^{9} / \mathrm{L}$ in men and $[0.36 \pm 0.17] \times 10^{9} / \mathrm{L}$ in women).

At visit 8 , after 3.5 years of follow-up, there were 66 HIV-positive subjects ( 41 men and 25 women) and $55 \mathrm{HIV}$-negative subjects ( 38 men and 17 women). Two men and four women seroconverted during the study.

Table 1. Six Neurologic Factors and Their Components*

\begin{tabular}{|c|c|c|c|}
\hline Factor & $\begin{array}{c}\text { Cut } \\
\text { Point }\end{array}$ & $\begin{array}{l}\text { No. of } \\
\text { Items } \\
\text { Included }\end{array}$ & ltems \\
\hline Symptoms & $\geq 3$ & 11 & $\begin{array}{l}\text { All cognitive, motor, and } \\
\text { behavioral items on } \\
\text { Price questionnaire }\end{array}$ \\
\hline $\begin{array}{l}\text { Fine limb } \\
\text { movements }\end{array}$ & $\geq 1$ & 8 & $\begin{array}{l}\text { Finger tapping, opening } \\
\text { and closing hands, } \\
\text { pronation, supination, } \\
\text { foot tapping }\end{array}$ \\
\hline Release reflexes & $\geq 3$ & 7 & $\begin{array}{l}\text { Glabellar, snout, suck, } \\
\text { palmomental reflexes, } \\
\text { grasp }\end{array}$ \\
\hline Cranial nerve & $\geq 2$ & 21 & All cranial nerve signs \\
\hline $\begin{array}{l}\text { Extrapyramidal } \\
\text { signs }\end{array}$ & $\geq 2$ & 13 & $\begin{array}{l}\text { Rigidity in all limbs, } \\
\text { bradykinesia, salivation, } \\
\text { gait, hypomimia, speech, } \\
\text { tremor (rest and action), } \\
\text { posture }\end{array}$ \\
\hline Sensory & $\geq 5$ & 16 & $\begin{array}{l}\text { Pain and temperature, } \\
\text { vibration, position. }\end{array}$ \\
\hline
\end{tabular}

*Each item is graded as 0 or 1 , and the maximum score is the number of items.
Men had 5.4 visits on average compared with 5.5 visits for women.

\section{PROGRESSION OF NEUROLOGIC FACTORS AND SUMMARY VARIABLES OVER TIME}

To assess the relationship between the development of neurologic impairment and severity of HIV infection, HIV-positive subjects were classified into four groups (asymptomatic, mildly symptomatic but insufficient for a diagnosis of ARC, ARC, and AIDS) at the visit when they first had a high score above the cut point on any individual neurologic factor. Similarly, they were classified by CD4 cell count $\left(\leq 0.2 \times 10^{4} / \mathrm{L}, 0.2\right.$ to $0.5 \times 10^{9} / \mathrm{L}$, and $\geq 0.5 \times 10^{9} / \mathrm{L}$ ) when they first demonstrated a significant neurologic end point (Table 3). Neurologic end points were reached by subjects at all stages of illness, but the majority of subjects reaching these end points had ARC. Women were less immunocompromised than men when they first developed EPS $(57.9 \%$ of the women had a CD4 cell count between $0.2 \times 10^{\circ}$ and $0.5 \times 10^{\circ} / \mathrm{L}$ ), while $39.1 \%$ of the men developed EPS when their CD4 cell count was in the $0.2 \times 10^{\circ}$ to $0.5 \times 10^{9} / \mathrm{L}$ range, although this was not significantly different. Approximately one third of the men and women had a CD4 cell count of $0.2 \times 10^{\circ} / \mathrm{L}$ or less when they developed generalized neurologic disability.

\section{LOGISTIC REGRESSION WITH REPEATED MEASURES}

\section{HIV-Positive vs HIV-Negative Women}

The independent effects of HIV status on the development of high scores in the neurologic domains were explored with adjusting for confounders such as education, history of head injury with loss of consciousness, and the age and substance abuse variable.

Certain neurologic outcomes were independently attributable to history of substance abuse. Subjects 40 years of age or younger with a long history of substance abuse were significantly more likely to have high factor scores

\section{Table 2. Baseline Demographics*}

\begin{tabular}{|c|c|c|c|c|}
\hline \multirow[b]{2}{*}{ Characteristic } & \multicolumn{2}{|c|}{ Men } & \multicolumn{2}{|c|}{ Women } \\
\hline & $\begin{array}{c}\text { HIV-Negative } \\
\quad(n=62)\end{array}$ & $\begin{array}{l}\text { HIV-Positive } \\
(n=85)\end{array}$ & $\begin{array}{c}\text { HIV-Negative } \\
(\mathrm{n}=37)\end{array}$ & $\begin{array}{c}\text { HIV-Positive } \\
(n=39)\end{array}$ \\
\hline Age, y & $39.6 \pm 7.6$ & $39.8 \pm 6.6$ & $37.4 \pm 7.9$ & $37.5 \pm 6.2$ \\
\hline Education, y & $120 \pm 2.2$ & $+1.4 \pm 2.1$ & $11.4 \pm 1.9$ & $12.1 \pm 1.8$ \\
\hline CD4 cell count, No. $\times 10^{8} / \mathrm{L}$ & $10+0.4$ & $0.4 \pm 0.3$ & $1.1 \pm 0.3$ & $0.4 \pm 0.3$ \\
\hline Global neurologic disability, score & $15 \pm 0.9$ & $1.9 \pm 0.8$ & $1.9 \pm 0.8$ & $2.2 \pm 0.8$ \\
\hline \multicolumn{5}{|l|}{ Race/ethnicity } \\
\hline Black & $44(71.0)$ & $63(75.9)$ & $21(56.8)$ & $28(71.8)$ \\
\hline White & $9(14.5)$ & $5(6.0)$ & $7(18.9)$ & $7(17.9)$ \\
\hline Hispanic & $9(14.5)$ & $15(18.1)$ & $9(24,3)$ & $4(10.3)$ \\
\hline Alcohol use $\geq 20 \mathrm{y}$ & $39(62.9)$ & $59(69.4)$ & $19(51,4)$ & $16(41.0)$ \\
\hline Drug use $\geq 15 y$ & $44(71.0)$ & $70(82.4)$ & $21(56.8)$ & $21(53.9)$ \\
\hline Any long-term substance abuse & $48(77.4)$ & $74(87.1)$ & $22(59.5)$ & $24(61.5)$ \\
\hline Head injury with $L O C$ & $26(41.9)$ & $40(47.1)$ & $10(27.0)$ & $12(30.8)$ \\
\hline
\end{tabular}

*HIV indicates human immunodeficiency virus; LOC, loss of consciousness. Values are either mean $\pm S D$ or number (percent). 
Table 3. Severity of HIV Infection and Immune Status at Visit When Neurologic Outcome Is First Demonstrated*

\begin{tabular}{|c|c|c|c|c|c|c|c|c|c|c|}
\hline \multirow[b]{3}{*}{ Factor } & \multicolumn{10}{|c|}{ No. $(\%)$ of Subjects With Outcome } \\
\hline & \multicolumn{5}{|c|}{ HIV Infection Severity } & \multicolumn{4}{|c|}{ CD4 Cell Count, $\times 10^{9} / \mathrm{L}$} & \multirow[b]{2}{*}{ Subtotal } \\
\hline & Asymptomatic & Mild & ARC & AIDS & Missing & $\geq 0.5$ & $0.2-0.5$ & $\leq 0.2$ & Missing & \\
\hline \multicolumn{11}{|l|}{ Men } \\
\hline Extrapyramidal signs $\geq 2$ & $2(4.3)$ & $7(15.2)$ & $33(727)$ & $4(8.7)$ & $\ldots$ & $7(15.2)$ & $18(39.1)$ & $18(39.1)$ & $3(6.5)$ & 46 \\
\hline Release reflexes $\geq 3$ & $2(11.1)$ & $3(16.7)$ & $13(72.2)$ & $0(0.0)$ & & $6(33.3)$ & $6(33.3)$ & $5(27.8)$ & $1(5.6)$ & 18 \\
\hline Neurologic disability $\geq 3$ & $4(6.7)$ & $5(21.7)$ & $40(66.7)$ & $3(5.0)$ & $\ldots$ & $12(20.0)$ & $25(41.7)$ & $20(33.3)$ & $3(5.0)$ & 60 \\
\hline \multicolumn{11}{|l|}{ Women } \\
\hline Extrapyramidal signs $\geq 2$ & $3(15.8)$ & $1(5.3)$ & $12(63.2)$ & $1(5.3)$ & $2(10.5)$ & $2(10.5)$ & $11(57.9)$ & $5(26.3)$ & $1(5.3)$ & 19 \\
\hline Release reflexes $\geq 3$ & $2(20.0)$ & $1(10.0)$ & $6(60.0)$ & $1(10.0)$ & & $3(30.0)$ & $3(30.0)$ & $4(40.0)$ & $0(0.0)$ & 10 \\
\hline Neurologic disability $\geq 3$ & $7(23.3)$ & $3(10.0)$ & $17(56.7)$ & $1(3.3)$ & $2(6.7)$ & $7(23.3)$ & $15(50.0)$ & $8(26.7)$ & $0(0.0)$ & 30 \\
\hline
\end{tabular}

*HIV indicates human immunodeficiency virus; AIDS, acquired immunodeficiency syndrome; and ARC, AIDS-related complex.

on fine limb movements (OR, 2.5; 95\% confidence interval $[\mathrm{Cl}], 1.3$ to 4.8 ), EPS (OR, 3.3; 95\% CI, 1.1 to 9.7), sensory abnormalities (OR, $4.1 ; 95 \% \mathrm{CI}, 1.8$ to 9.5 ), and release reflexes (OR, 3.7; 95\% $\mathrm{CI}, 1.1$ to 12.5 ) than those 40 years of age or younger with a short history of substance abuse. Subjects older than 40 years of age with a long history of substance abuse were more likely to have greater neurologic disability (scored as $\geq 3$ ) (OR, 4.3; $95 \%$ CI, 1.9 to 9.6), high EPS scores (OR, 5.7; 95\% CI, 2.2 to 14.6), and sensory abnormalities (OR, 3.0; 95\% CI, 1.4 to 6.5 ) than subjects 40 years of age or younger with a short history of substance abuse.

Recent alcohol or other drug abuse $(6$ months prior to interval), dichotomized into high and low, was not significantly related to the development of any of the neurologic outcomes.

Education was negatively correlated with abnormalities of fine limb movements, EPS, sensory abnormalities, and neurologic disability. Women with a history of head injury were twice as likely to have cranial nerve abnormalities (OR, 2.06; 95\% CI, 1.1 to 4.0 ). At every visit, HIV-positive women were 2.4 times more likely to have neurologic disability (scored as $\geq 3$ ) than were HIV-negative women, after adjusting for the independent effects of age, education, history of head injury, and substance abuse. No HIV by length of follow-up interactions was observed, suggesting that, over time, HIVpositive women were no more likely to develop high factor scores than were HIV-negative women.

\section{HIV-Positive vs HIV-Negative Men}

The 147 HIV-positive and HIV-negative men were analyzed similarly. As in the women, there were neurologic signs independently attributable to substance abuse. Men 45 years of age or younger with longtime substance abuse were more likely to have fine limb movement abnormalities (OR, 2.3; $95 \% \mathrm{CI}, 1.3$ to 4.0 ) than were men 45 years of age or younger with a short history of substance abuse. Men older than 45 years of age with longtime substance abuse were significantly more likely to have cranial nerve abnormalities (OR, 3.1;95\% CI, 1.5 to 6.3), fine limb movement abnormalities (OR, 2.7; $95 \% \mathrm{Cl}, 1.5$ to 5 ), and release reflexes (OR, $10.0 ; 95 \% \mathrm{Cl}$, 1.2 to 86.7 ) than were men 45 years of age or younger with a short history of substance abuse.
As in the women, no relationship between recent alcohol or other drug use and the neurologic domains was seen, except for neurologic symptoms. Those with high recent alcohol or other drug use were more likely to report symptoms than were those with low recent alcohol or other drug use (OR, 1.76; 95\% CI, 1.06 to 2.94).

Education was inversely correlated with EPS, abnormalities of fine limb movements, and global neurologic impairment. As with the women, men with a history of head injury with loss of consciousness were twice as likely to have cranial nerve abnormalities (OR, $2.0 ; 95 \% \mathrm{CI}, 1.3$ to 3.0 ). Over time, both HIV-positive and HIV-negative men were likely to develop neurologic disability (scored as $\geq 3$ ) (OR, $1.4 ; 95 \% \mathrm{CI}, 1.2$ to $1.6)$ and to have sensory abnormalities (OR, 1.6;95\% CI, 1.4 to 1.8 ). At each visit, HIV-positive men had a higher likelihood of having a neurologic disability (OR, 1.9; $95 \%$ $\mathrm{CI}, 1.1$ to 3.2) and were more likely to have cranial nerve abnormalities (OR, 1.5; 95\% CI, 1.0 to 2.3 ) and fine limb movement abnormalities (OR, $1.8 ; 95 \% \mathrm{CI}, 1.2$ to 2.8 ) than HIV-negative men. Over the course of follow-up, HIV-positive men were more likely to report HIVrelated symptoms than were HIV-negative men (OR, 1.4; $95 \% \mathrm{CI}, 1.1$ to 1.8 ) and were more likely to have EPS than were HIV-negative men (OR, 1.6; 95\% CI, 1.2 to 2.3 ) (Figure).

\section{HIV-Positive Women Only}

Analysis was then restricted to the $43 \mathrm{HIV}$-positive women (Table 4). Four women seroconverted during the follow-up period. They were included within the HIVpositive group at the visit when they were first determined to be HIV-positive. In the first analysis, covariates included in the model were age at each visit, education, history of head injury, and CD4 cell count $\left(\leq 0.2 \times 10^{9}\right.$ and $0.2 \times 10^{9}$ to $0.5 \times 10^{9} \mathrm{~L}$, with a CD4 cell count of $\geq 0.5 \times 10^{9} / \mathrm{L}$ as a reference group). Recent substance abuse was initially included as a covariate in the model and was not related to the development of any of the neurologic outcomes. Because information was available for only visits 2 through 7 , which resulted in a smaller data set, this variable was not included in the final model. History of substance abuse was not included in the model because it was highly correlated with age. 


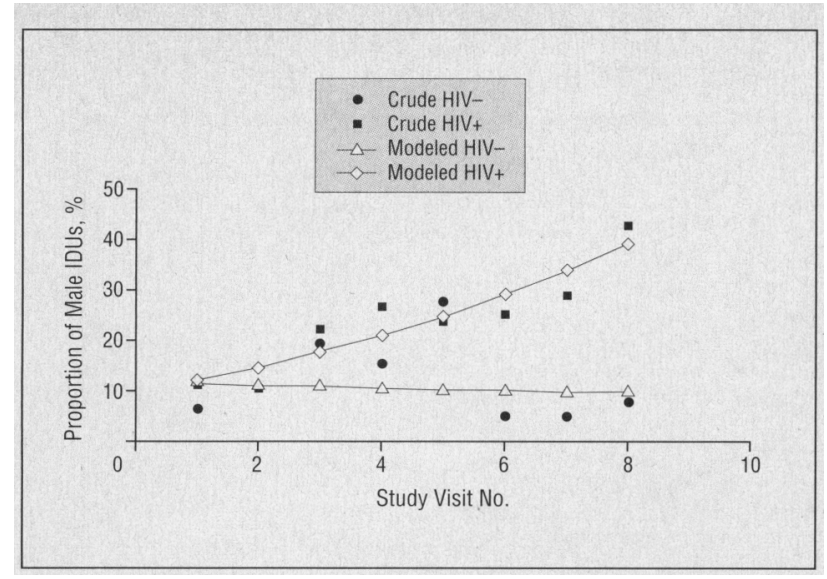

Proportion (\%) of male intravenous drug users (IDUS) on each visit who have extrapyramidal signs: crude vs modeled human immunodeficiency virus (HIV). Plus sign indicates positive; minus sign, negative.

By adjusting for the effects of age, education, and history of head injury, the odds of developing significant EPS and cranial nerve signs were increased in women with a CD4 cell count of $0.2 \times 10^{9} / \mathrm{L}$ or less compared with those with a CD4 cell count of $0.5 \times 10^{9} / \mathrm{L}$ or greater. By adjusting for age, education, or head injury, women with AIDS (1986 definition) were over five times as likely to have a neurologic disability and 11 times as likely to have neurologic symptoms than were women with no symptoms or mild symptoms. Women with AIDS were significantly more likely to have neurologic disability (scored as $\geq 3)$ than were women with ARC $(P<.05)$. Comparison of women who had ARC with those who had no symptoms or mild symptoms revealed no differences.

\section{Relationship of Neurologic and Neuropsychologic Outcomes}

The presence or development of neurologic disability (scored as $\geq 3$ ) was associated with poorer performance on the language and motor speed factors $(P<.05)$ and weakly associated with the memory $(P<.07)$ and attention $(P<.06)$ factors.

\section{HIV-Positive Men Only}

Eighty-six HIV-positive men, including two men who seroconverted during the follow-up period, were included in an analysis identical to that done for the HIVpositive women (Table 5). In the first model, covariates included age, education, history of recent substance abuse, history of head injury with loss of consciousness, and CD4 cell count (categories $\leq 0.2 \times 10^{9}$ and 0.2 to $0.5 \times 10^{9} / \mathrm{L}$ compared with the $\geq 0.5 \times 10^{9} / \mathrm{L}$ category as a reference). Recent substance abuse was associated only with the high neurologic symptom scores (OR, $1.7 ; 95 \% \mathrm{CI}$, 1.1 to 1.4$)$. In the final model, excluding recent substance abuse, CD4 cell counts between $0.2 \times 10^{9} / \mathrm{L}$ and $0.5 \times 10^{9} / \mathrm{L}$ and a $\mathrm{CD} 4$ cell count of $0.2 \times 10^{9} / \mathrm{L}$ or less were associated with EPS, fine limb movement abnormalities, sensory impairment, and significant neurologic disability compared with those with a CD4 cell count of $0.5 \times 10^{9} / \mathrm{L}$ or greater. None of the other neurologic out- comes were associated with low CD4 cell count. In the second analysis, HIV stage was substituted for the CD4 cell count as a covariate. Men with ARC or AIDS had a greater likelihood of having neurologic disability symptoms, fine limb movement abnormalities, and EPS than did men with no symptoms or with mild symptoms. Men with AIDS were over nine times more likely to have neurologic disability than were men with no symptoms or with mild symptoms and were also more likely to have neurologic complaints. Only the OR for generalized neurologic disability was significantly higher for those with AIDS than ARC.

\section{Relationship of Neurologic and Neuropsychologic Outcomes}

There was a significant association between the development of neurologic disability and poor performance on memory, executive function, language, attention, and motor speed factors.

\section{COMMENT}

\section{RELATIONSHIP BETWEEN SUBSTANCE ABUSE AND HIV INFECTION IN WOMEN AND MEN}

Determining the neurologic signs and symptoms attributable to HIV-1 infection in IDUs poses challenges not apparent in the analysis of HIV infection in homosexual and bisexual men. Intravenous drug users may be immunosuppressed even in the absence of HIV infection. ${ }^{27}$ The proportion of women and minorities represented among IDUs has led to a redefinition of AIDS-defining illness ${ }^{2}$ to include recurrent bacterial pneumonia, pulmonary tuberculosis, and cervical carcinoma to better depict the spectrum of illness in this risk group. Polysubstance abuse, the high frequency of reported head injury, and concomitant nutritional deficiencies might make it more likely to observe neurologic impairment in IDUs than in homosexual or bisexual men and more difficult to discern the independent effects of HIV on the nervous system. Furthermore, male and female IDUs may have different neurologic profiles. This might reflect differences in the type and frequency of substance abuse and the pattern of substance abuse, once systemic illness is evident.

In this sample, women were more likely to reduce their drug use when they developed AIDS. The CD4 cell counts may not accurately reflect the degree of illness in women compared with men. In an analysis of the CD4 cell counts at which $50 \%$ of HIV-infected but AIDS-free IDUs had ARC based on three biannually measured CD4 cell counts in this cohort, female IDUs had a median CD4 cell count of $0.76 \times 10^{9} / \mathrm{L}$ compared with $0.42 \times 10^{9} / \mathrm{L}$ in male IDUs, suggesting that the CD4 cell count might not accurately reflect the extent of systemic illness, particularly in female IDUs. ${ }^{28}$ Our findings of a higher frequency of women first presenting with significant EPS when the CD4 cell count was in the 0.2 to $0.5 \times 10^{9} / \mathrm{L}$ range compared with men supports the notion that women may present with neurologic illness at an earlier stage of immunocompromise than men. It is unlikely that this is at- 


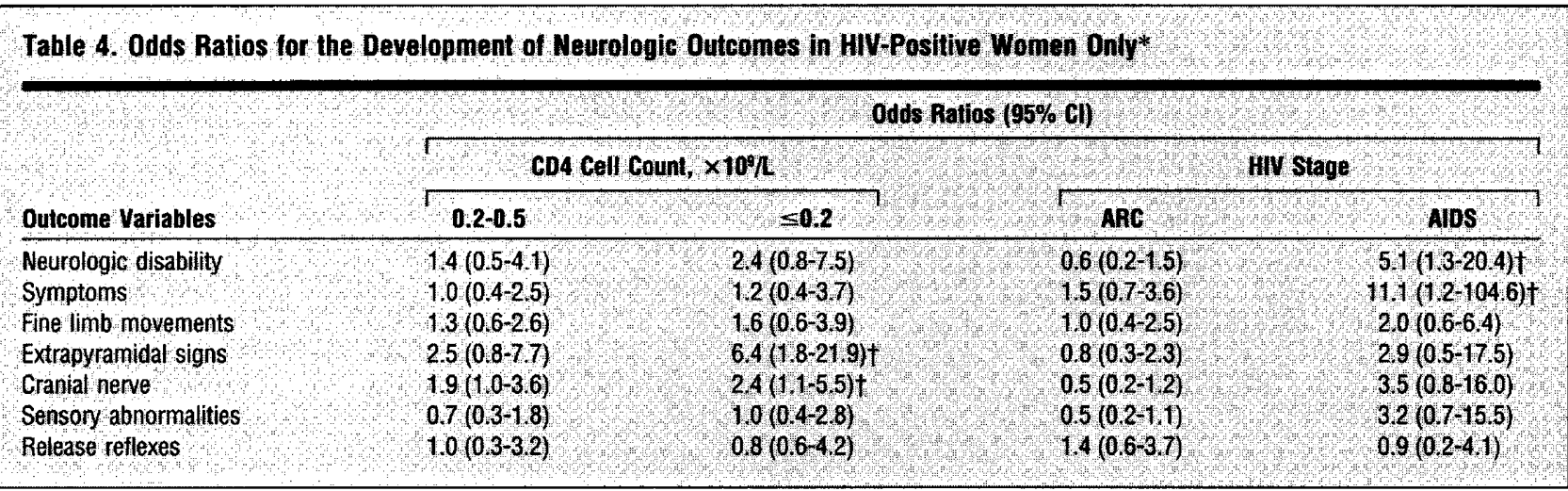

*HIV indicates human immunodeficiency virus; CI, confidence interval; AIDS, acquired immunodeficiency syndrome; and ARC, AIDS-related complex. $\dagger P<.05$; adjusted for age, education, and head injury.

\begin{tabular}{|c|c|c|c|c|}
\hline \multirow[b]{3}{*}{ Outcome Variables } & \multicolumn{4}{|c|}{ Odds Ratlos $(95 \% \mathrm{cI})$} \\
\hline & \multicolumn{3}{|c|}{ CD 4 cell count, $\times 10^{\circ} \mathrm{L}$} & \\
\hline & $0.2-0.5$ & $\leq 0.2$ & ARC & ADs \\
\hline Neurologic disability & $20(1137) t$ & $3.0(1.6-5.7) \mathrm{t}$ & $2.2(1.3-3.8) \mathrm{f}$ & $9.3(2.0-43.6) t$ \\
\hline Symptoms & $12(0.6-22)$ & $1.3(0.5-2.9)$ & $2.6(1.4-4.8) \mathrm{t}$ & $4.0(1.1-14.7) t$ \\
\hline Fine limb movements & $17(11-27) t$ & $18(1.0-3.1))$ & $20(1.1-3.7) t$ & $2.6(0.8-8.3)$ \\
\hline Extrapyramidal signs & $29(1.3-6.7) t$ & $3.8(1.6-9.0) t$ & $2.9(1.4-5.8) 1$ & $3.6(1.1-12.2) t$ \\
\hline Cranial nerve & $0.8(0.4-16)$ & $0.9(0.5-1.7)$ & $16(0929)$ & $0.9(0.42 .3)$ \\
\hline Sensory abnormalities & $21(1,-3.8) t$ & $13(0.7-2.4)$ & $1.0(0.6-1.8)$ & $1.4(0.4-4.8)$ \\
\hline Release reflexes & $11(0.524)$ & $0.7(0.2-2.1)$ & $1.1(0.43 .1)$ & $1.5(0.3-6.7)$ \\
\hline
\end{tabular}

*HIV indicates human immunodeficiency virus; $C l$, confidence interval; AIDS, acquired immunodeficiency syndrome; and ARC, AIDS-related complex. $\nmid \mathrm{P}<.05$; adjusted for age, education, and head injury.

tributable to selective early mortality in men. Baseline CD4 cell counts were similar in men and women overall. The baseline CD4 cell counts of men and women who were eventually unavailable for follow-up or who died were similar. The numbers of visits for men and women were almost identical.

Progression of neurologic illness may follow a different course in men and women. This issue can only be properly addressed in a matched analysis comparing men and women with similar age, immunologic status, and stage of illness, resulting in a much smaller sample size. This will be reported separately.

Several important observations emerged from the longitudinal follow-up of these 223 IDUs. Human immunodeficiency virus-positive women were more likely to have neurologic impairment than were HIV-negative women, independent of the effects of age, education, head injury, and drug and alcohol use. Women with a CD4 cell count of $0.2 \times 10^{9} / \mathrm{L}$ or less were over six times as likely to have EPS and twice as likely to have cranial nerve abnormalities compared with those with a CD4 cell count of $0.5 \times 10^{9} / \mathrm{L}$ or greater, while women with AIDS (1986 definition) were over five times as likely to have global neurologic impairment and over 11 times as likely to have neurologic symptoms as were HIV-infected women with no symptoms or with mild symptoms. Findings in the men were more varied. Compared with HIV-negative men, HIV-positive men were more likely to have a neurologic disability, fine limb movement abnormalities and cranial nerve abnormalities, and, over time, EPS and neurologic symptoms were more likely to occur in HIVpositive men than in HIV-negative men. In men, there was a clear association between systemic illness (defined clinically as ARC or AIDS) and the odds of having fine limb movement abnormalities, EPS, and neurologic symptoms. A declining CD4 cell count was also associated with the presence of neurologic signs. Because these relationships held after adjusting for age (correlated with substance use history), education, and head injury, we believe that these neurologic findings are attributable to HIV infection and not to substance abuse. In both men and women, neurologic impairment was associated with neuropsychologic impairment in the domains of motor speed and language, while men also demonstrated an association with executive function, memory, and attention.

\section{NEUROLOGIC MANIFESTATIONS OF CHRONIC SUBSTANCE ABUSE}

Tremor and parkinsonism are well-known complications of alcohol and opioid abuse, notably MPTP (1methyl-4-phenyl-1,2,3,6-tetrahydropyridine), ${ }^{29}$ while tics and dystonia are more often associated with cocaine use. ${ }^{30}$ After controlling for substance abuse, parkinsonism and fine limb movement abnormalities were a prominent fea- 
ture, particularly in HIV-infected men. There was no association between recent substance abuse and these outcomes.

\section{SELECTIVE VULNERABILITY OF THE BASAL GANGLIA IN ADVANCED HIV INFECTION}

The prominent EPS and fine limb movement abnormalities seen in HIV-positive men and women, particularly those with greater systemic illness or immunocompromise, parallel our findings in 207 homosexual men who were followed up prospectively over 4.5 years, ${ }^{14}$ suggesting that HIV has similar effects on the nervous system, regardless of risk group. There are several lines of evidence in the neuropathologic and radiologic literature to support the idea that the basal ganglia are particularly vulnerable in HIV infection. Quantitative magnetic resonance imaging analysis has shown a stronger association of the bicaudate ratio, a measure of atrophy in the caudate nucleus with HIV dementia, than the ventricle-brain ratio, a measure of generalized atrophy ${ }^{31}$ Similarly, HIV-infected patients with dementia could be distinguished from patients without dementia based on smaller basal ganglia volumes, after correction for intracranial volume. ${ }^{32}$ These changes have not been replicated in HIV-infected subjects with no symptoms or with mild symptoms when nonquantitative measures of atrophy with magnetic resonance imaging were used. ${ }^{33,34}$ In both children ${ }^{35}$ and adults, ${ }^{36}$ neuropathologic evidence of inflammatory infiltrates predominate in the basal ganglia and are accompanied by diffuse white matter astrocytosis. The possibility that HIV-1-associated neuronal damage might be mediated via the NMDA ( $N$-methyl-Daspartate) receptor ${ }^{37}$ coupled with the demonstration of increased quinolinate in the cerebrospinal fluid of patients with dementia ${ }^{38}$ also points to the basal ganglia as a location for HIV-mediated damage. Therefore, the association of extrapyramidal features and fine limb movement abnormalities in immunosuppressed, systemically ill HIV-positive IDUs is not surprising, although impairment in fine alternating movement might also reflect cortical involvement, especially given the high frequency of head injury.

There are some limitations to this study. We could not determine whether those who are immunocompromised gradually worsen neurologically or whether there is a sudden decline in neurologic function when a certain immunologic status is reached.

The study was designed to describe the relationship between neurologic, neuropsychologic, and medical findings early in the course of HIV infection. Few subjects reached the end points of severe neurologic impairment (eg, dementia) over the 3.5-year period. The differences between HIV-positive and HIV-negative men and women may be underestimated because HIVpositive subjects were often not examined when they became extremely ill, and only subjects who were ambulatory were examined.

Because the incidence of HIV-associated neurologic illnesses is increased in those with a CD4 cell count under $0.1 \times 10^{9} / \mathrm{L}$ and antiretroviral use does not provide protection against the development of dementia and may actually worsen peripheral neuropathy, it is important to be aware of these findings in drug users. ${ }^{39}$ As HIVinfected individuals live longer, even in the setting of greater immunocompromise, the neurologic manifestations of HIV infection in this rapidly expanding population are bound to increase.

Accepted for publication June 16, 1995.

From the Departments of Neurology (Drs Marder, Stern, Malouf, Dooneief, Williams, and Bell and Mr Todak) and Psychiatry (Drs Stern, Ehrhardt, Stein, Williams, and Gorman and Mr Todak), College of Physicians and Surgeons, the Gertrude H. Sergievsky Center (Drs Marder, Liu, Stern, Dooneief, Bell, and Stein); the HIV Center for Clinical and Behavioral Studies (Drs Marder, Liu, Stern, Malouf, Dooneief, Bell, Sorrell, El Sadr, Ehrhardt, Stein, Williams, and Gorman and Mr Todak and Ms Joseph); the Division of Epidemiology, School of Public Health at Columbia University (Dr Stein); Harlem Hospital Center (Drs Malouf and El Sadr and Ms Joseph); and St Luke'sRoosevelt Hospital Center (Dr Sorrell), New York, NY.

This research was supported by center grant P50MH43520 from the National Institute of Mental Health/ National Institute on Drug Abuse, Rockville, Md, to the HIV Center for Clinical and Behavioral Studies at the New York State Psychiatric Institute in New York; by grant T32MH19139 from the National Institute of Mental Health; and by grants 3-M01-RR00645 and AG 10963 from the National Institutes of Health, Bethesda, Md.

Reprint requests to Gertrude H. Sergievsky Center, 630 W 168th St, Box 16, New York, NY 10032 (Dr Marder).

\section{REFERENCES}

1. Des Jarlais D, Friedman SR, Choopanya K, Vanichseni S, Ward T. International epidemiology of HIV and AIDS among injecting drug users. AIDS. 1992;6: 1053-1068.

2. Centers for Disease Control and Prevention. HIV/AIDS Surveillance Report. Atlanta, Ga: CDC; October 1993:1-19.

3. O'Connor P, Selwyn P, Schottenfeld R. Medical care for injection-drug users with human immunodeficiency virus infection. N Engl J Med. 1994;331:450459 .

4. Selnes 0 , McArthur J, Royal W III, et al. HIV-1 infection and intravenous drug use: longitudinal neuropsychological evaluation of asymptomatic subjects. Neurology. 1992;42:1924-1930.

5. McKegney F, O'Dowd M, Feiner C, Selwyn P, Drucker E, Friedland G. A prospective comparison of neuropsychologic function in HIV seropositive and seronegative methadone-maintained patients. AIDS. 1990;4:565-569.

6. Egan V, Brettly R, Goodwin G. The Edinburgh cohort of HIV-positive drug users: pattern of cognitive impairment in relation to progression of disease. $\mathrm{BrJ}$ Psychiatry. 1992;161:522-531.

7. Marder K, Stern Y, Malouf R, et al. Neurologic and neuropsychological manifestations of human immunodeficiency virus infection in intravenous drug users without acquired immunodeficiency syndrome: relationship to head injury. Arch Neurol. 1992;49:1169-1175

8. El-Sadr W, Goetz R, Sorrell S, Joseph M, Ehrhardt A, Gorman J. Clinical and laboratory correlates of human immunodeficiency virus infection in a cohort of intravenous drug users from New York, NY. Arch Intern Med. 1992;152: 1653-1659.

9. American Psychiatric Association. Diagnostic and Statistical Manual of Mental Disorders, Revised Third Edition. Washington, DC: American Psychiatric Association; 1987.

10. Centers for Disease Control. CDC classification system for human Tlymphotropic virus type III/lymphadenopathy-associated virus infections. MMWR Morb Mortal Wkly Rep. 1986;35:334-339.

11. Gorman JM, Kertzner R, Todak G, et al. Multidisciplinary baseline assessment of homosexual men with and without human immunodeficiency virus infec- 
tion, I: overview of study design. Arch Gen Psychiatry. 1991;48:120-123.

12. Fahn S, Marsden C, Calne D, eds. Recent Developments in Parkinson's Dis ease. Florham Park, NJ: Macmillan Healthcare Information; 1987;2:153-163.

13. Price RW, Brew B, Sidtis J, Rosenblum M, Sheck A, Cleary P. The brain in AIDS: central nervous system HIV- 1 infection and AIDS dementia complex. Science. 1988;239:586-592.

14. Marder K, Liu X, Stern Y, et al. Neurologic signs and symptoms in a cohort of gay men followed for 4.5 years. Neurology. 1995;45:261-266.

15. Kurtzke JF. Rating neurologic impairment in multiple sclerosis: an expanded disability status scale (EDSS). Neurology. 1983;33:1444-1452.

16. Stern $Y$, Marder $K$, Bell $K$, et al. Multidisciplinary baseline assessment of homosexual men with and without human immunodeficiency virus infection, III: neurologic and neuropsychologic findings. Arch Gen Psychiatry. 1991;48:131138.

17. Stern Y, Liu X, Marder K, et al. Neuropsychological changes in a prospectively followed cohort of gay and bisexual men with and without HIV. Neurology. 1995; 45:467-472

18. Buschke $H$, Fuld PA. Evaluating storage, retention, and retrieval in disordered memory and learning. Neurology. 1974;24:1019-1025.

19. Klove H. Clinical neuropsychology. Med Clin North Am. 1963;46:1647-1658.

20. Tuokko $H$, Vernon-Wilkinson $R R$, Weir J, Beattie BL. Cued recall and early identification of dementia. J Clin Exp Neuropsychol. 1991;13:871-879.

21. Reitan R. Validity of the Trail Making Test as an indicator of organic brain damage. Percept Mot Skills. 1958:8:271-276

22. Goodglass H, Kaplan E. The Assessment of Aphasia and Related Disorders 2nd ed. Philadelphia, Pa: Lea \& Febiger; 1983.

23. Wechsler D. Wechsier Adult Intelligence Scale Revised. New York, NY: The Psychological Corp; 1981.

24. Sano M, Rosen W, Mayeux R. Attention deficits in Alzheimer's disease. Presented at the American Psychological Association 1984. (Abstract).

25. Folstein MF, Folstein SE, McHugh PR. 'Mini-Mental State': a practical method for grading the cognitive state of patients for the clinician. $J$ Psychiatr Res. 1975;12:189-198

26. Liang KY, Zeger SL. Longitudinal data analysis using generalized linear models. Biometrika. 1986;73:13-22.

27. Weber $R$, Band $L$, de Costa $B$, et al. Neural control of immune function: opi- oids, opioid receptors, and immunosuppression. In: Harris L, ed. Problems of Drug Dependence 1990. Rockville, Md: National Institute on Drug Abuse; 1991; 96. US Dept of Health and Human Services research monograph 105.

28. Paik M, Begg M, El-Sadr W, Gorman J, Stein Z. Difference in clinical implications of CD4 counts among HIV-infected homosexual men, injection drug using men and women. Stat Med. In press.

29. Langston J, Ballard P, Tetrud J, Irwin L. Chronic parkinsonism in humans due to a product of meperidine-analog synthesis. Science. 1983;219:979.

30. Cardoso F, Jankovic J. Movement disorders. Neurol Comp Drug Alcohol Abuse. 1993:11:625-638.

31. Dal Pan G, McArthur J, Aylward E, et al. Patterns of cerebral atrophy in HIV-1 infected individuals: results of a quantitative MRI analysis. Neurology. 1992; 42:2125-2130

32. Aylward $\mathrm{E}$, Henderer $\mathrm{J}, \mathrm{McArthur} \mathrm{J}$, et al. Reduced basal ganglia volume in HIV-1 associated dementia: results from quantitative neuroimaging. Neuro/ogy. 1993;43:2099-2104.

33. Dooneief $G$, Bello J, Todak G, et al. A prospective controlled study of magnetic resonance imaging of the brain in gay men and parenteral drug users with human immunodeficiency virus infection. Arch Neurol. 1992;49:38-43.

34. McArthur JC, Cohen B, Selnes 0 , et al. Low prevalence of neurological and neuropsychological abnormalities in otherwise healthy HIV-1 infected individuals: results from the Multicenter AIDS Cohort Study. Ann Neurol. 1989;26: 601-611.

35. Michaels J, Sharer L, Epstein L. Human immunodeficiency virus type-1 (HIV-1) infection of the nervous system: a review. Immunodefic Rev. 1988;1: 71-104.

36. Navia B, Cho E, Petito C, Price R. The AIDS dementia complex, II: neuropathology. Ann Neurol. 1986;19:523-535.

37. Lipton S, Sucher N, Kaiser P, Dreyer E. Synergistic effects of the HIV coat protein and NMDA receptor-mediated neurotoxicity. Neuron. 1991;7:111-118.

38. Heyes M. Brew B, Martin A, et al. Quinolinic acid in cerebrospinal fluid and serum in HIV-1 infection: relationship to clinical and neurological status. Ann Neurol. 1991;29:202-209.

39. Bacellar H, Munoz A, Miller E, et al. Temporal trends in the incidence of HIV-1 related neurologic diseases: multicenter AIDS cohort study, 1985-1992. $\mathrm{Neu}$ rology. 1994;44:1892-1900.

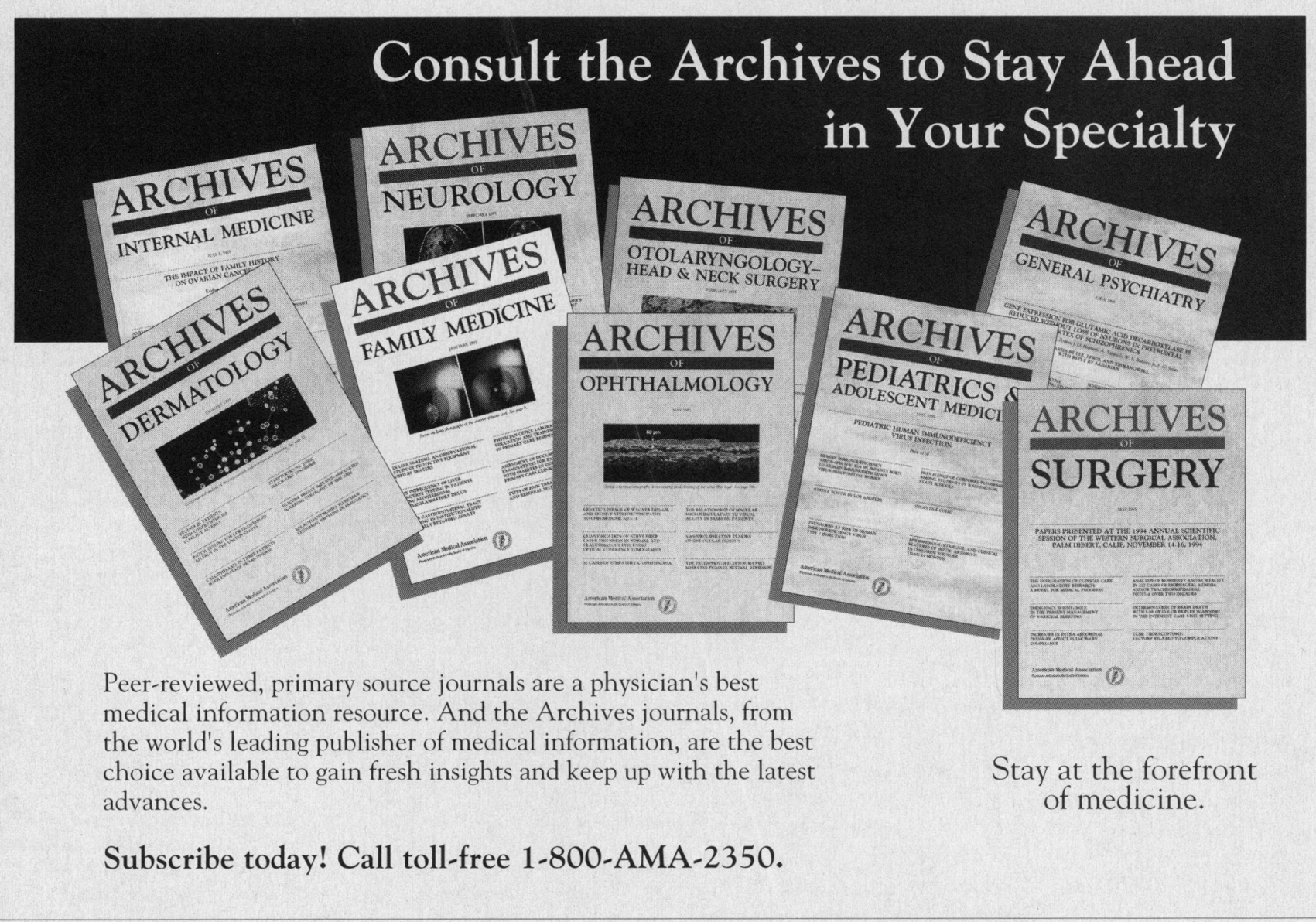

